\title{
Bactericidal Potency of Green Synthesized Silver Nanoparticles against Waterborne Escherichia coli Isolates
}

\author{
Dalal Mohammed Ridha, Hawraa Mohammed AL-Rafyai, NoorSaad Najii \\ Department of Biology, College of Science, University of Babylon, Iraq. \\ Corresponding author. E-mail: sci.dalal.showali@uobabylon.edu.iq
}

Received: Aug. 3, 2020; Accepted: Aug. 5, 2021; Published: Nov. 22, 2021

Citation: Dalal M. Ridha, Hawraa M. AL-Rafyai, and Noor S. Najii, Bactericidal Potency of Green Synthesized Silver Nanoparticles against Waterborne Escherichia coli Isolates. Nano Biomed. Eng., 2021, I3(4): 372-379. DOI: 10.5101/nbe.v13i4.p372-379.

\begin{abstract}
In recent years, silver nanoparticles (Ag NPs) had produced by biological methods such as plant extract due to their efficiency, low cost, being non-toxic, and ecofriendly nature. Ag NPs have antibacterial, anti-mold, and anti-fungi because of their high surface area to volume ratio. In this study, Opuntia ficus-indica (Prickly pear) extract was used to produce green synthesized Ag NPs. Different techniques had adopted to describe the generated nanoparticles, such as an ultraviolet spectrophotometer, Transmission Electron Microscopy (TEM), Dynamic Light Scattering (DLS), and Zeta Potential Analysis. Escherichia coli (E. coli), separated from sediment and water of the Hillah River in Babylon city in Iraq, was utilizedto estimate the antibacterial activities of Ag NPs at different concentrations. Both broth microdilution assay and well diffusion assay were applied. The Congo Red Agar implied to investigate the ability of E. coli isolates to form a biofilm. The TEM images of Ag NPs illustrated spherical morphology with a diameter of approximately $22 \pm 4 \mathrm{~nm}$. The antibacterial activity tests showed that the Minimum Inhibitory Concentration (MIC) ranged from $0.0125 \mathrm{mg} \cdot \mathrm{L}^{-1}$ to $0.05 \mathrm{mg} \cdot \mathrm{L}^{-1}$, whereas Minimum Bactericidal Concentration (MBC) was from $0.025 \mathrm{mg} \cdot \mathrm{L}^{-1}$ to 0.05 $\mathrm{mg} \cdot \mathrm{L}^{-1} .5 \mathrm{~h}$ ofexposure to the $0.025 \mathrm{mg} \cdot \mathrm{L}^{-1}$ concentrations of the Ag NPs had a bactericidal impact on $92 \%$ of the $E$. coli isolates. In our study, we found silver nanoparticles synthesized by Opuntia ficus-Indica have antibacterial activity against waterborne Escherichia coli isolates and it could be utilizedtoreduce microbial growth in contaminated water.
\end{abstract}

Keywords: Bactericidal impact, Biofilm, Green synthesis, Silver nanoparticles, Opuntia ficus-indica extract, Waterborne E. coli

\section{Introduction}

The transmissionof pathogens occurred by drinkingandrunning water, remains thecause of illness and death, especially in undeveloped countries [1]. Around one billion humans lack safe and clean drinking water.Approximately two million people die each year from drinking polluted water [2]. Theaquatic environment had corrupted by human activities such as watersheds, agriculture, or rivers near wastewaterdischarges $[3,4]$. The increased drainage of sewage directly into streams is a significant source of antibiotic-resistant bacteria.Their resistance genes had transmitted by horizontal gene transfer to bacteria in natural bacterial communities [5]. Contamination of aquatic environments with pathogens represents a health hazard and a direct threat to drinking water supply, recreational activities, and crop irrigation 
[6]. E. coli found in the humans' feces and other warm-blooded animals stand as evidence of fecal contamination. Which can survive for a long time in river water [3, 7]. Previous studies have indicated $E$. coli is acrucial repository for Multiple drug resistance (MDR) genes, so it is anadequateagent for transferring resistance genes in the bacterial community [8, 9]. Several studies suggestthat the origin of MDR genes is strains of $E$. coli isolated from animals. However, some researchers pointed out that water is a vital mediator for MDR proliferation, which leads to the prevalence of carrying-MDR bacteria in the aquatic environment [10]. Nanotechnology refers to all developed technologies in various fields such as medicine, pharmacy, and cosmetics working with nanoscale dimensions ranged from $1 \mathrm{~nm}$ to $100 \mathrm{~nm}$ [11]. Green synthesis is an alternative method of producing nanoparticles. It is cost-effective, time-consuming, and does not require toxic substances that affect living organisms and the environment. Lately, many metal nanoparticles such as gold, silver, and copper nanoparticles have been produced using phytochemical agents in plant extracts [12]. The selection of eco-friendly nanoparticles requires accurate experiments in which the shape, size, anddynamics of the interaction between the metal ions, and the reducing agents, are studied [13]. Ag $\mathrm{NP}$ also gained interestamong nanoparticles due to their size-dependent properties, including chemical, catalytic, electrical, and antimicrobial impacts. Ag NPs had synthesized by biological methods, which have distinctive properties, such as increased surfacearea, small scale, and high dispersion, which improve the antimicrobial impact of Ag NPs relative to silver elements. The production of nanoparticles in different shapes and sizes belongs to various plant essences. With the increased antimicrobial consequences of silver at the Nanoscale, Ag NPs had employed to control a wide range of pathogens [14]. Ag NPshadextensively adoptedin the food industry, water purification, and antimicrobial agents against MDR bacteria [15].

In the present study, various methodshave beenused in vitro to determine the antibacterial effect of green synthesized Ag NPs. The antibacterial activity of green synthesized Ag NPs had examined against E. coli samples isolated from water and sediment of the Hillah River in Babylon city. Moreover, the bactericidal effect of Ag NPs was investigated against E. coli isolates exposed to different concentrations during the first $5 \mathrm{~h}$. At the same time, the impact of different concentrations of Ag NPs on the ability of isolates to form biofilm had also studied.

\section{Experimental Description of thesampling area}

Although the Hillah River in Babylon, Iraq, is the foremost water source for thecity's residents, pollution sources have spread along the river, such as sewagedrainage and agricultural wastes. The water and sediment sampleshad taken from three chosenregionsdepending on the causes of contamination. The first region is adjacent to thefarming field, the second region is near Marjan Hospital, and the third region is in urbanized areas.

\section{Preparation of stem extract and AgNPs}

Due to the existence of antioxidants in Opuntia ficus-indica extract (prickly pear), that was used as a reducing agent in the green synthesis of silver nanoparticles [16]. Stems of Opuntia ficus-indica were washed several times with sterilized deionized water to remove dirt and dust. Later $2.5 \mathrm{~g}$ of the stems were chopped into small pieces and boiled in 100 $\mathrm{mL}$ deionized water for $10 \mathrm{~min} .13 \mathrm{~mL}$ of the filtersterilized extract was diluted and $\mathrm{pH}$-adjusted to the final volume of $100 \mathrm{~mL}$ and the $\mathrm{pH}$ value of 9, using deionized water and $0.1 \mathrm{M} \mathrm{NaOH}$. Silver nitrate solution $(1 \mathrm{~mL})(0.01 \mathrm{M})$ was added to the mixture drop by drop and stirred using a magnetic stirrer with a speed of $500 \mathrm{rpm}$ for $24 \mathrm{~h}$. After the synthesis of Ag NP, the solution containing nanoparticles was rinsed three times with deionized water and discard by centrifuge at 12000 RCF for 30 min to detach Ag NP. The sediment was suspended with deionized water and kept at laboratory temperature for the following experiments.

\section{Sample characterization}

The ultraviolet-visible spectrum was measured using a spectrophotometer (Analytik Jena - Specord 210 ) in the 200-800 $\mathrm{nm}$ wavelength range. The shape and size of the synthesized Ag NPs, as well as the selected area electron diffraction (SAED), were analyzed by Transmission Electron Microscopy (TEM) (JEM2000EX; JEOL, Tokyo, Japan), conducted at 200 kV. Dynamic Light Scattering (DLS) analysis (Horiba SZ-100; Kyoto, Japan) was used to define the dimensional feature and dispersity of the synthesized Ag NPs. The surface charge of Ag NPs was evaluated by determining the Zeta potential (Horiba SZ-100; Kyoto, Japan). 


\section{E. coli isolation}

Microorganisms of the water and sediment samples were separated by filtration using the sterilized membrane filters $(0.45 \mu \mathrm{m}$ pore size $)$. The applied membranes were placed on E. coli-Enterobacteria chromogenic agar plates (Condalab, Spain). The presumptive E. coli colonies were further analyzed using the Enterosystem 18 R kit (Liofilchem-Italy), and the confirmed $E$. coli isolates were obtained for further experiments.

\section{Determination of the biofilm-forming isolates}

The Congo red agar (CRA) was prepared depending on the procedure stated by Freeman. et al. [17]. The components of the medium included the Brain Heart Infusion Broth (HiMedia, India) (37 $\left.\mathrm{g} \cdot \mathrm{L}^{-1}\right)$, sucrose (50 $\left.\mathrm{g} \cdot \mathrm{L}^{-1}\right)$, Agar-Agar type 1 (HiMedia, India) $\left(10 \mathrm{~g} \cdot \mathrm{L}^{-1}\right)$, and Congo red dye (HiMedia, India) $\left(8 \mathrm{~g} \cdot \mathrm{L}^{-1}\right)$. The Congo red dye was dissolved in distilled water and autoclaved separately for $15 \mathrm{~min}$ at $121{ }^{\circ} \mathrm{C}$. The sterilized dye solution was added to the sterilized medium, which cooled down to $55^{\circ} \mathrm{C}$. The prepared CRA Petri plates were kept refrigerated until being used. The E. coli isolates were cultured on CRA plates and incubated at $37^{\circ} \mathrm{C}$ for $24 \mathrm{~h}$ to evaluate their biofilm-producing ability. The presence of black colonies on CRA refers to the biofilmsformation [18].

\section{Identification of the antimicrobial activity by the well diffusion assay}

The antibacterial activity of green synthesized Ag NPs was estimated using the well-diffusion method. The E. coli isolates were cultivated on a Brain Heart Infusion Agar (BHIA) (HiMedia, India) at $37^{\circ} \mathrm{C}$ for $18 \mathrm{~h}$. Three to five single colonies were transferred into normal saline to obtain bacterial suspension equal to the 0.5 McFarland. Shortly, Mueller-Hinton agar (MHA) (HiMedia, India) plates were cultured with 0.5 McFarland bacterial suspensions under aseptic conditions. Six pits with $5 \mathrm{~mm}$ diameter were made on the inoculated MHA, and $50 \mu \mathrm{L}$ of sequentially decreasing concentrations of the Ag NPs were transferred into the wells as the following: $0.8,0.4$, $0.2,0.1,0.05$, and $0.025 \mathrm{mg} \cdot \mathrm{L}^{-1}$. Imipenem disc (10 $\mu \mathrm{g})$ was used asnegative control, and distilled water as positive control. Finally, inoculated plates were incubated for $24 \mathrm{~h}$ at $37^{\circ} \mathrm{C}$. The diameter of the inhibition zone around every pit reflects the green synthesized Ag NPs' antimicrobial activity.
Identification of the minimum inhibitory concentration and the minimum bactericidal concentration of green synthesized silver nanoparticles

Broth microdilution technique was performed according to the CLSI standard (M07A9, 2012) to determine The MIC and MBC of the green synthesized Ag NPs. Firstly, broth serial dilutions of Ag NPs were achieved in $(50 \mu \mathrm{L})$ sterilized Müller Hinton broth (HiMedia, India) in the wells of microtiterplate to obtain the following concentrations: 0.4, 0.2, 0.1, 0.05, 0.025 , and $0.0125 \mathrm{mg} \cdot \mathrm{L}^{-1}$. A $50 \mu \mathrm{L}$ of bacterial suspension with $1 \times 10^{6} \mathrm{CFU} / \mathrm{mL}$ concentration was transferred to each well containing Ag NPs. Imipenem was used as negative control, and distilled water as positive control. The inoculated microtiter plates were incubated at 37 for $24 \mathrm{~h}$. The lowest concentration of Ag NPs, which resulted in no visible growth, was regarded as MIC. MBC was determined as the lowest concentration of Ag NPs resulting in deletion of $99.9 \%$ of initial inoculum and was detected by the cultivation of the contents of every growth-inhibited well in BHI agar and colony counting after $24 \mathrm{~h}$ incubation at $37^{\circ} \mathrm{C}$.

\section{Evaluation of the viability and biofilm formation ability during $5 \mathrm{~h}$ exposure to the green synthesized Ag NPs}

Bactericidal and anti-biofilm potencies of various concentrations of Ag NPs were determined in 1-h intervals during a 5-h exposure time. The broth microdilution method was applied according to the CLSI standard (M07A9, 2012). Broth serial dilutions of Ag NPs were made in $(50 \mu \mathrm{L})$ sterilized Müller Hinton broth (HI Media, India) in the wells of microtiterplate to obtain the following concentrations: $0.4,0.2,0.1,0.05,0.025$ and $0.0125 \mathrm{mg} \cdot \mathrm{L}^{-1}$. A $50 \mu \mathrm{L}$ of bacterial suspension with $1 \times 10^{6} \mathrm{CFU} / \mathrm{mL}$ concentration was transferred to each well containing Ag NPs. A 10-microliter portion of every well was transferred and spread on TSA plates at 1-h intervals. The TSA plates were incubated at $37^{\circ} \mathrm{C}$ for $24 \mathrm{~h}$ and colony counted to find out the $\mathrm{MBC}$ at the related time of exposure. Also, a 5-microliter portion was taken from every well at the 1-h intervals and streaked on CRA plates to investigate the capacity of biofilm formation of the $E$. coli isolates exposed to the various concentrations of Ag NPs for 1 to $5 \mathrm{~h}$. The CRA plates were incubated at $37^{\circ} \mathrm{C}$ for $24 \mathrm{~h}$. The appearance of black colonies was regarded as the biofilm formation ability, according to Freeman, et al. [17]. 


\section{Results and Discussion Spectrophotometer analysis}

Adding silver nitrate solution to Opuntia ficus-indica extract changes thesolution color from light yellow to dark brown. The emergence of the brown color belongs to the excitation of the Surface Plasmon Resonance (SPR) and the reduction of silver nitrate solution by the plant extract [19]. As depicted in (Fig. 1), the typical absorption peak at $420 \mathrm{~nm}$ in the ultraviolet-visible spectrum showed the formation of Ag NPs.

\section{Transmission electron microscopy (TEM) analysis}

The TEM image of the green synthesized Ag NPs sample displayed spherical morphology of NPs, and a bit of agglomeration (Fig. 2). The average diameter of Ag NP was estimated at $22 \pm 4 \mathrm{~nm}$. The selected area electron diffraction (SAED) pattern, illustrated in (Fig. 2(d)), was indexed for Ag NPs. (ICDD no: 05-0664)

\section{Dynamic light scattering (DLS) analysis}

DLS analysis was performed to estimate the dispersion size of Ag NPs in the aquatic environment.
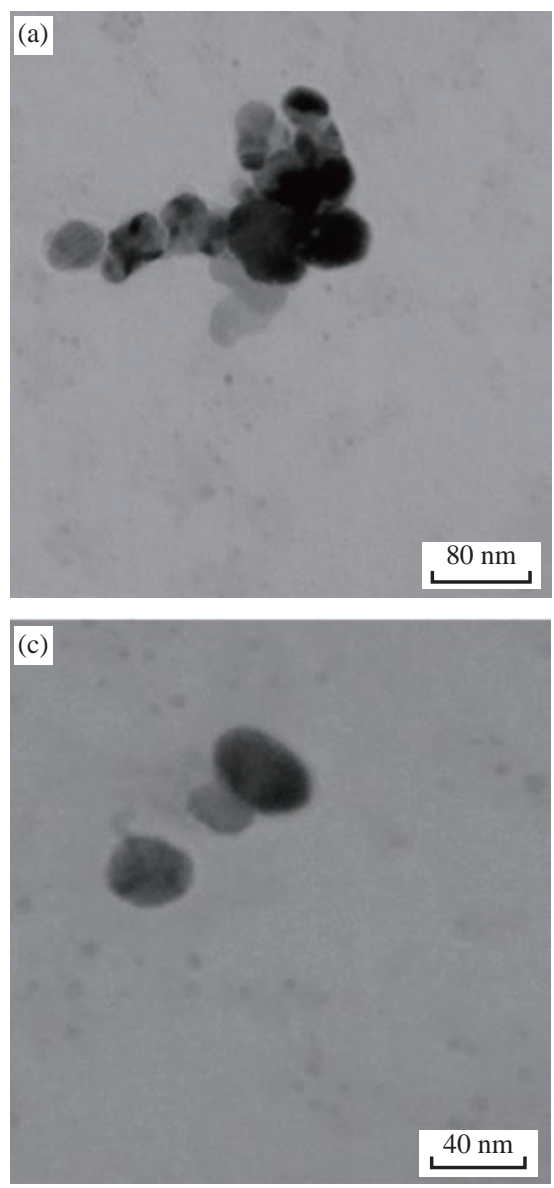

This procedure was done at $25{ }^{\circ} \mathrm{C}$ in a standard dispersed medium, at a viscosity of $0.892 \mathrm{mPa} \cdot \mathrm{s}$. As shown in (Fig. 3), aparticle size distribution of obtained Ag NPs was ranging between $60 \mathrm{~nm}$ to110 nm with an average peak value of $76 \mathrm{~nm}$. The results of the DLS analysis revealed the polydispersity index (PDI) of green synthesized Ag NPs was 0.716, indicating broad range of different size of generated Ag NPs.

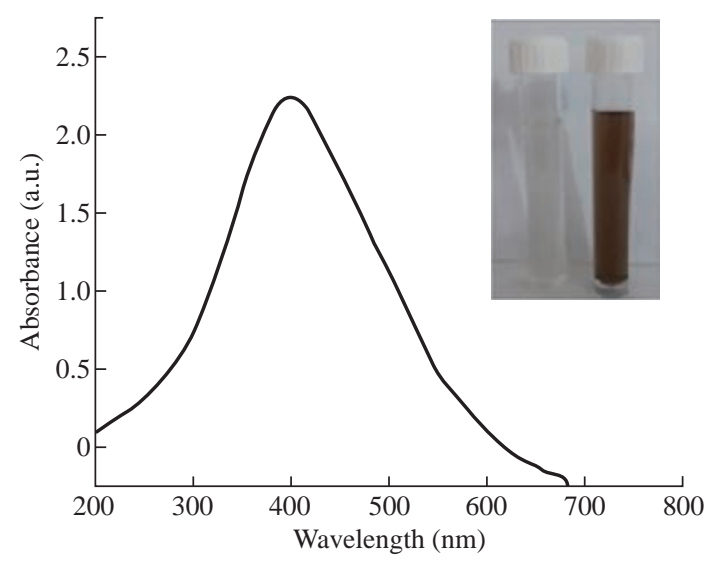

Fig. 1 UV-visible spectra of the green synthesized silver nanoparticles.
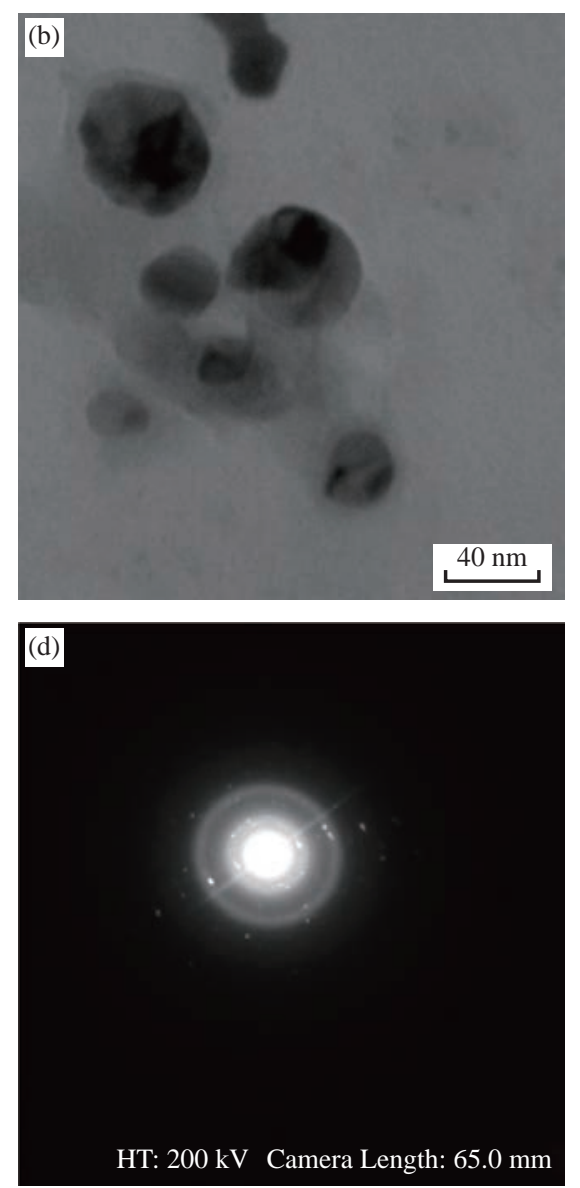

Fig. 2 Transmission electronic microscope image of green synthesized silver nanoparticles in different sizes. (a) $80 \mathrm{~nm}$, (b) $40 \mathrm{~nm}$, (c) $40 \mathrm{~nm}$, and (d) SAED pattern. 


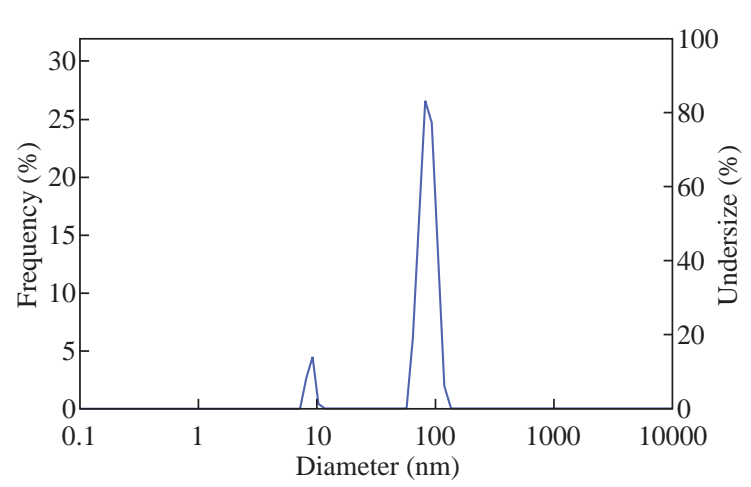

Fig. 3 Dynamic light scattering pattern of the green synthesized silver nanoparticles.

\section{Zeta potential analysis}

Zeta potential of Ag NPs was analyzedto evaluate the stability of suspension. It is well known that NP with a surface charge higher than $+30 \mathrm{mV}$ or less than $-30 \mathrm{mV}$ exhibit more stability and dispersion in liquid [20]. As a result, the zeta potential diagram of Ag NPs revealed that the surface charge of Ag NPs is $-66.3 \mathrm{mV}$ (Fig. 4). The high negativity of the zeta potential value might be relating to the capping agent existing in the stem extract of the Opuntia ficus-indica.

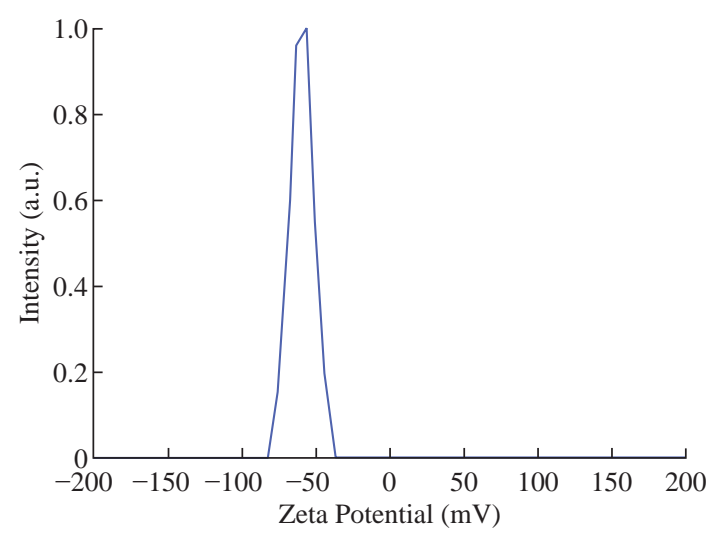

Fig. 4 Zeta potential of the green synthesized silver nanoparticles.

\section{Determination of the biofilm-forming isolates}

Based on CRA culture results, $85 \%$ of the $E$. coli isolate (50 out of 59) had black colonies with a crystalline appearance and were regarded as the biofilm-forming isolates. The non-biofilm-forming isolates were distinguished as white colonies on CRA.

\section{Identification of the antimicrobial activity by the well diffusion assay}

The well-diffusion assay was conducted to evaluate the susceptibility of the $E$. coli isolates against various concentrations of the green synthesized Ag NPs. The inhibition zone diameter ranged from 2 to $15 \mathrm{~mm}, 11$ to $14 \mathrm{~mm}, 10$ to $13 \mathrm{~mm}, 9$ to $12 \mathrm{~mm}, 7$ to $10 \mathrm{~mm}$, and 6 to $9 \mathrm{~mm}$ by the Ag NPs concentration of $0.8,0.4,0.2$, $0.1,0.05$, and $0.025 \mathrm{mg} \cdot \mathrm{L}^{-1}$ respectively, as depicted in (Fig. 5(a)). The inhibition zone ranged from 12 to $15 \mathrm{~mm}, 11$ to $14 \mathrm{~mm}, 10$ to $13 \mathrm{~mm}, 9$ to $12 \mathrm{~mm}, 7$ to $10 \mathrm{~mm}$, and 6 to $9 \mathrm{~mm}$ at $0.8,0.4,0.2,0.1,0.05$, and $0.025 \mathrm{mg} \cdot \mathrm{L}^{-1}$ respectively. Based on the results of the repeated measures ANOVA with a GreenhouseGeisser correction determined that the mean inhibition zone varied statically significantly betweendifferent concentrations $(\mathrm{F}(3.224,157.955)=1604.807$, $\mathrm{P}<0.0005)$. Post hoc tests using the Bonferroni revealed a significant difference at 0.05 level between the diameters of inhibition zones at various concentrations as shown in (Fig. 5(b)). The results demonstrated that the diameters of the inhibition zone decreased when the concentrations of Ag NP decreased. These results had confirmed by the results of Pal et al. [21].

\section{Identification of the minimum inhibitory concentration and the minimum bactericidal concentration of green synthesized silver nanoparticles}

The green synthesized Ag NPs exhibited
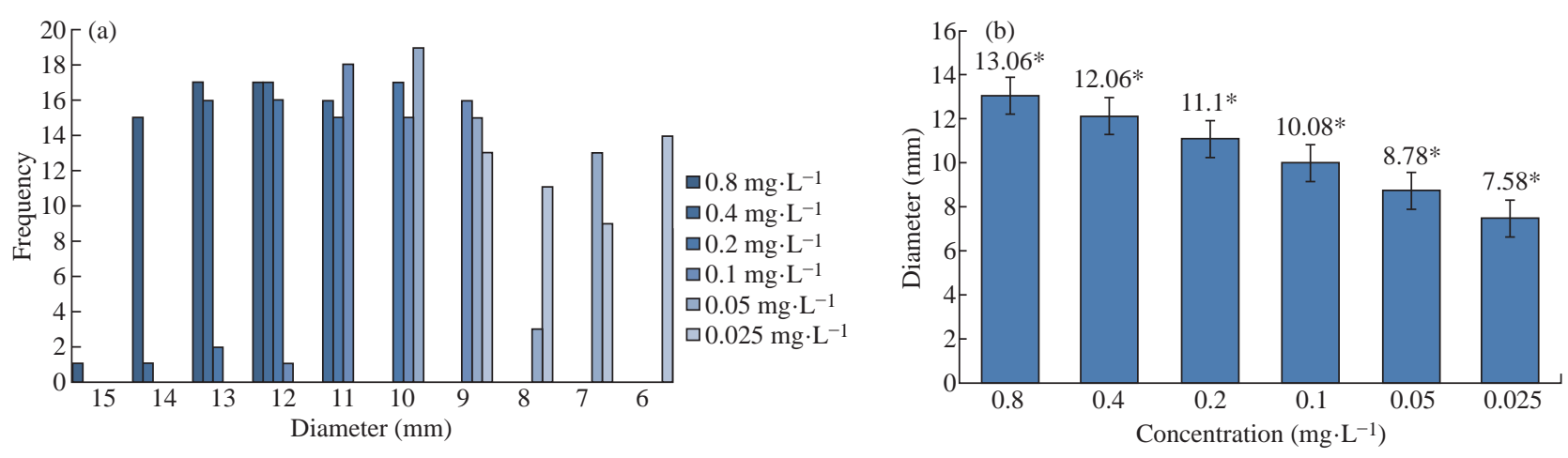

Fig. 5 Antimicrobial activity the green synthesized silver nanoparticles by the well diffusion assay. (a) Inhibition zone of the green synthesized silver nanoparticles at various concentrations. (b) Average diameter of inhibition zone of the green synthesized silver nanoparticles at various concentrations. (The small stars represented significant difference at the 0.05 level.) 

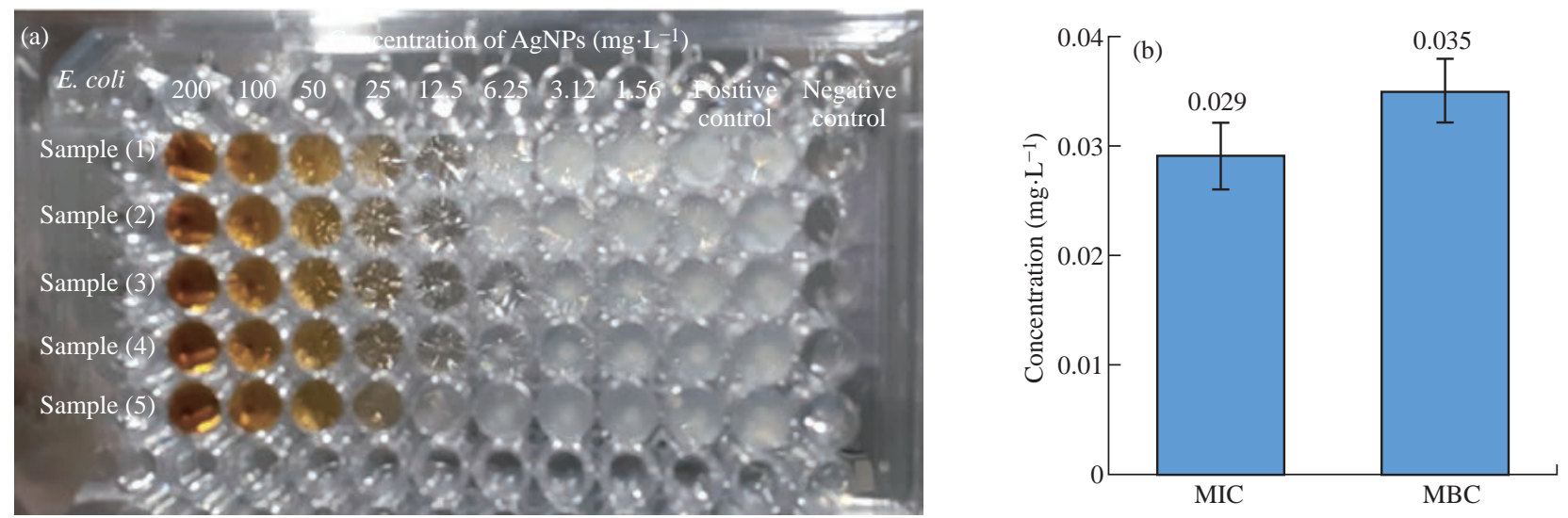

Fig. 6 (a) The antibacterial activity of the green synthesized Ag NPs against E. coli isolates. (b) Average MIC\&MBC of Ag NPs.

antibacterial activity against $E$. coli isolates. The lowest concentration with no visible growth and the lowest concentration eliminating $99.9 \%$ of the inoculum has counted MIC and MBC of the Ag NP, respectively. The MIC of Ag NPs against the E. coli isolates ranged from 0.0125 to $0.05 \mathrm{mg} \cdot \mathrm{L}^{-1}$. The Ag NPs revealed bactericidal characteristics and had MBC values of 0.025 and $0.05 \mathrm{mg} / \mathrm{L}$ against the E. coli isolates (Fig. 6). The small size of Ag NPs displays a much higher dissolution rate that leads to a greater level of toxicity. The antibacterial activity mechanism of Ag NPs involves the incorporation of silver ions with thiol groups in biological molecules such as enzymes and other proteins. That prevents cell division and destroys the cell envelope. Also, silver ions have high affinity to react with sulfurcontaining bases than phosphate groups in nucleic acids [22]. Silver ions released from Ag NPs can tightly attach to cells, suppress enzyme activity, damage cell membranes, and drove cell death [23]. Antimicrobial activity with aratio of MBC to MIC $\leq$ 4 is described as a bactericidal effect [24]. The green synthesized Ag NPs revealed a bactericidal feature against $100 \%$ of the $E$. coli isolates. Values of the MBC to MIC ratio exhibited the bactericidal impact of that green synthesized Ag NPs against $100 \%$ of the $E$. coli isolates. The previous studies revealed that antibacterial agents with bactericidal impact work on the rapid elimination of the infectious agents preventing the spread of infection and growth of the resistant strains [25]. The different MIC and MBC values against the $E$. coli isolates in this study may be attributable to the developed resistance against Ag NPs. The constant exposure of E. coli against silver nanoparticles creates resistance to silver nanoparticles. This resistance is due to the generation of the flagellin protein, which causes accumulation of the nanoparticles and decreases their suspensionstability and results in diminishing their antibacterial activity [26]. The mut $\mathrm{Y}$, mutS, mutM, and mutT genes in E. coli are thought to be responsible for the regeneration of Ag NP-induced DNA damage. As a result, the mutation in these genes made the bacteria more susceptible to Ag NP. Mutations in the OmpF and OmpC purine coding genes, which involve the formation of water-filled channels in the outer membrane of Escherichia coli, lead to Ag NPs resistance [27].

\section{Evaluation of the viability and biofilm formation ability during 5-h exposure to the green synthesized Ag NPs}

In this study, the E. coli isolates were exposed to different concentrations of Ag NPs for $5 \mathrm{~h}$, and the bactericidal and anti-biofilm properties were determined at various times of exposure to the different Ag NPs concentrations by culturing on TSA and CRA, respectively. The Ag NPs revealed antibacterial effect in a time and dose-dependent manner. After 1-h exposure, the 0.4, 0.2, and 0.1 $\mathrm{mg} \cdot \mathrm{L}^{-1}$ concentrations of the Ag NPs resulted in at least $3-\log$ reduction in the bacterial count of 46, 22, and $12 \%$ of the $E$. coli isolates. The lower concentrations neither resulted in a 3-log reduction in the bacterial count nor exhibited the anti-biofilm activity. The longer the time of exposure, the higher the frequency of the affected $E$. coli isolates. Finally, 92, 84, 58, and $38 \%$ of the $E$. coli isolates experienced at least a 3-log population reduction, after $5 \mathrm{~h}$ of exposure to the $0.4,0.2,0.1,0.05$, and $0.025 \mathrm{mg} \cdot \mathrm{L}^{-1} \mathrm{Ag}$ NPs concentrations (Fig. 7). None of the growing $E$. coli isolates exhibited loss of biofilm formation ability due to the various exposure times to the different concentrations of the Ag NPs. 


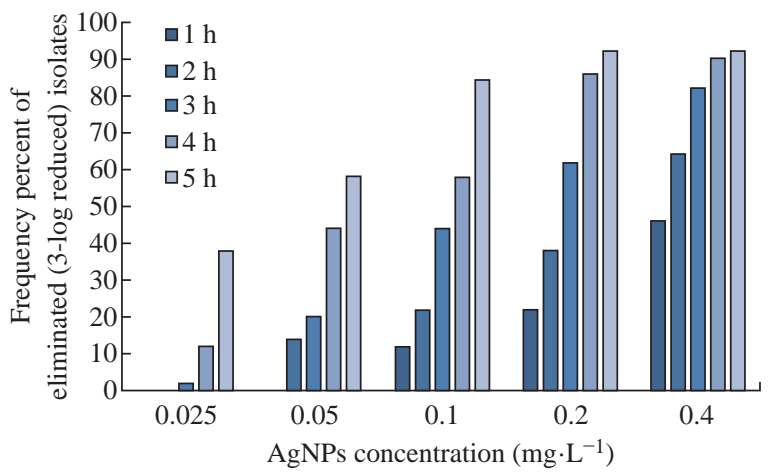

Fig. 7 The bactericidal activity of different concentrations of the green synthesized Ag NPs against the E. coli isolates during the 5-h period.

\section{Conclusions}

The green synthesis of nanoparticles from plant extract is considered a promising low-cost, environmentally friendly method, which does not need any poisonous chemicals for synthesis. The leaf extract of Opuntia ficus-indica was utilized to produce the silver nanoparticles in a spherical shape with an average size of $20 \mathrm{~nm}$. The green synthesized silver nanoparticles exhibited significant antibacterial activity against $E$. coli isolates in the range of $0.0125-0.05 \mathrm{mg} \cdot \mathrm{L}^{-1}$. The current study showed green synthesized silver nanoparticles do not affect the ability of E. coli isolates to generate biofilm, even in low concentrations. The use of green synthesized silver nanoparticles in the wastewater treatment process may effectively eradicate the pathogens by releasing the silver ions from the surface of the nanoparticles in aquatic environments. The silver ions are involved in the production of reactive oxygen species (ROS), leading to the destruction of the bacterial genome, protein degradation, and the permeability of cell membranes.

\section{Funding}

The authors didn't take any financial assistance from any organization.

\section{Abbreviations}

Ag NPs: Silver nanoparticles; BHIA: Brain heart infusion agar; CRA: Congo red agar; DLS: Dynamic light scattering; E. coli: Escherichia coli; MBC: Minimum bactericidal concentration; MIC: Minimum inhibitory concentration; MDR: Multiple drug resistance; MHA: Mueller-Hinton agar; SAED; Selected area electron diffraction; SPR: Surface Plasmon resonance; TSA: Tryptic soy agar; TEM: Transmission electron microscopy.

\section{Conflicts of Interests}

The authors declare no conflicts of interests.

\section{References}

[1] R. Dosoky, S. Kotb, and M. Farghali, Efficiency of silver nanoparticles against bacterial contaminants isolated from surface and ground water in Egypt. Journal of Advanced Veterinary and Animal Research, 2015, 12: 175-184.

[2] D. van Halem, H. van der Laan, S.G.J. Heijman, et al., Assessing the sustainability of the silver-impregnated ceramic pot filter for low-cost household drinking water treatment. Physics and Chemistry of the Earth, 2009, 34: 36-42.

[3] R. Maal-Bared, K.H. Bartlett, W.R. Bowie, et al, Phenotypic antibiotic resistance of Escherichia coli and E. coli $\mathrm{O} 157$ isolated from water, sediment and biofilms in an agricultural watershed in British Columbia. Science of the Total Environment, 2013, 443: 315-323.

[4] X. Zhang, Y. Li, B. Liu, J. Wang, et al., Prevalence of veterinary antibiotics and antibiotic-Resistant Escherichia coli in the surface water of a livestock production region in northern China. PLoS One, 2014.

[5] J.A. Port, A.C. Cullen, J.C. Wallace, et al., Metagenomic frameworks for monitoring antibiotic resistance in aquatic environments. Environmental health perspectives, 2014, 122: 222-228.

[6] P.K. Pandey, P.H. Kass, M.L. Soupir, et al., Contamination of water resources by pathogenic bacteria. AMB Express, 2014, 4: 1-16.

[7] A. Pereira, A. Santos, M. Tacão, et al., Genetic diversity and antimicrobial resistance of Escherichia coli from Tagus estuary (Portugal). Science of the Total Environment, 2013, 461: 65-71.

[8] F. Arsène-Ploetze, O. Chiboub, D. Lièvremont, et al., Adaptation in toxic environments: comparative genomics of loci carrying antibiotic resistance genes derived from acid mine drainage waters. Environmental Science and Pollution Research, 2018, 25: 1470-1483.

[9] A.A.S. Katakweba, A.P. Muhairwa, A.M. Lupindu, et al., First Report on a Randomized Investigation of Antimicrobial Resistance in Fecal Indicator Bacteria from Livestock, Poultry, and Humans in Tanzania, Microb. Microbial Drug Resistance, 2018, 24: 260-268.

[10] J. Jang, H.G. Hur, M.J. Sadowsky, et al., Environmental Escherichia coli: ecology and public health implications. Journal of Applied Microbiology, 2017, 123: 570-581.

[11] G. Morose, The 5 principles of "Design for Safer Nanotechnology”. Journal of cleaner production, 2010, 18: 285-289.

[12] T. Shafiq, M. Uzair, M.J. Iqbal, et al., Green synthesis of metallic nanoparticles and their potential in bio-medical applications. Nano Biomed Eng, 2021, 13: 191-206.

[13] K.A.D. Guzmán, M.R. Taylor, and J.F. Banfield, Environmental risks of nanotechnology: National nanotechnology initiative funding. National Nanotechnology Initiative Funding, 2006, 40: 1401-1407.

[14] I. Sondi, B. Salopek-Sondi, Silver nanoparticles as antimicrobial agent: A case study on E. coli as a model for 
Gram-negative bacteria. Journal of Colloid and Interface Science, 2004, 275: 177-182.

[15] N. Silvestry-Rodriguez, K.R. Bright, D.C. Slack, et al., Silver as a residual disinfectant to prevent biofilm formation in water distribution systems. Applied and environmental microbiology, 2008, 74: 1639-1641.

[16] F.U. Khan, Y. Chen, N.U. Khan, et al., Antioxidant and catalytic applications of silver nanoparticles using Dimocarpus longan seed extract as a reducing and stabilizing agent. Journal of Photochemistry and Photobiology B: Biology, 2016, 164: 344-351.

[17] D.J. Freeman, F.R. Falkiner, and C.T. Keane, New method for detecting slime production by coagulase negative staphylococci. Journal of Clinical Patholgy, 1989, 42: 872-874.

[18] A. Hassan, J. Usman, F. Kaleem, et al., Evaluation of different detection methods of biofilm formation in the clinical isolates. Brazilian Journal of Infectious Diseases, 2011, 15: 305-311.

[19] P. Mulvaney, Surface plasmon spectroscopy of nanosized metal particles. The Journal of Physical Chemistry B, 1996, 12: 788-800.

[20] J.D. Clogston, A.K. Patri, Zeta potential measurement. Methods of Molecular Biology, 2011, 697: 63-70.

[21] S. Pal, Y.K. Tak, and J.M. Song, Does the antibacterial activity of silver nanoparticles depend on the shape of the nanoparticle? A study of the gram-negative bacterium Escherichia coli. Applied and Environmental Microbiology, 2007, 73: 1712-1720.
[22] G. Mcdonnell, A.D. Russell, Antiseptics and disinfectants: Activity, action, and resistance. Clinical Microbiology Reviews, 1999, 12: 147-179.

[23] S. Tang, J. Zheng, Antibacterial activity of silver nanoparticles: Structural effects. Advanced Healthcare Materials, 2018, 7: 1-10.

[24] H.H. Lara, N.V. Ayala-Núñez, L.C.I. del Turrent, et al., Bactericidal effect of silver nanoparticles against multidrug-resistant bacteria. World Journal of Microbiology and Biotechnology, 2010, 26: 615-621.

[25] G.L. French, Bactericidal agents in the treatment of MRSA infections-The potential role of daptomycin. Journal of Antimicrobial Chemotherapy, 2006, 58: 11071117.

[26] A. Panáček, L. Kvítek, M. Smékalová, et al., Bacterial resistance to silver nanoparticles and how to overcome it. Nature Nanotechnology, 2018, 13: 65-71.

[27] M.A. Radzig, V.A. Nadtochenko, O.A. Koksharova, et al., Antibacterial effects of silver nanoparticles on gramnegative bacteria: Influence on the growth and biofilms formation, mechanisms of action. Colloids and Surfaces B: Biointerfaces, 2013, 102: 300-306.

Copyright $@$ Dalal M. Ridha, Hawraa M. AL-Rafyai, and Noor S. Najii. This is an open-access article distributed under the terms of the Creative Commons Attribution License, which permits unrestricted use, distribution, and reproduction in any medium, provided the original author and source are credited. 